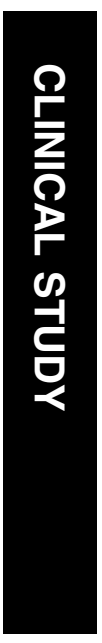

\title{
Second-eye cataract surgery in elderly women: a cost-utility analysis conducted alongside a randomized controlled trial
}

${ }^{1}$ School of Chemical Sciences and Pharmacy, University of East Anglia, Norwich, UK

${ }^{2}$ Health Economics Group, Institute of Health and Social Sciences Research, Faculty of Health, University of East Anglia, Norwich, UK

${ }^{3}$ Department of Ophthalmology, Queen's Medical Centre, Nottingham University Hospitals NHS Trust, Nottingham, UK

${ }^{4}$ Clinical Gerontology Research Unit, Nottingham University Hospitals, Nottingham, UK

Correspondence: TH Sach, School of Chemical Sciences and Pharmacy,

University of East Anglia, Earlham Road,

Norwich NR4 7TJ,

UK

Tel: + 441603592022 ;

Fax: +44 1603592003

E-mail: T.Sach@uea.ac.uk

Received: 4 November 2008 Accepted in revised form: 16 April 2009

Published online: 15 May 2009

\begin{abstract}
Aim The aim of this study was to evaluate the cost-effectiveness of second-eye cataract surgery for older women with minimal visual dysfunction in the eye to be operated on from a Health and Personal Social Services perspective, compared to waiting list controls who had already undergone first-eye cataract surgery.
\end{abstract}

Methods A cost-utility analysis was undertaken alongside a randomized controlled trial of second-eye cataract surgery in secondary care ophthalmology clinics.

A total of 239 women over 70 years old with one unoperated cataract were randomized to cataract surgery (expedited, approximately 4 weeks) or control (routine surgery, 12 months wait). Outcomes were measured in terms of quality-adjusted life years (QALYs), with health-related quality of life estimated using the EuroQol EQ-5D.

Results The operated group had costs which were, on average, $£ 646$ more than the control group (95\% confidence interval, £16-1276, $P<0.04)$ and had a mean QALY gain of 0.015 (95\% confidence interval, -0.039 to 0.068 , $P=0.59)$ per patient over 1 year. Therefore, the incremental cost-utility ratio was $£ 44263$ over the 1-year trial period. In an analysis modelling costs and benefits over patients' expected lifetime, the incremental cost per QALY was $£ 17299$, under conservative assumptions.

Conclusions Second-eye cataract surgery is not likely to be cost-effective in the short term for those with mild visual dysfunction pre-operation. In the long term, second-eye cataract surgery appears
TH Sach ${ }^{1,2}$, AJE Foss ${ }^{3}$, RM Gregson ${ }^{3}$, A Zaman $^{3}$, F Osborn $^{3}$, T Masud ${ }^{4}$ and RH Harwood ${ }^{4}$

to be cost-effective unless carer costs are included.

Eye (2010) 24, 276-283; doi:10.1038/eye.2009.112; published online 15 May 2009

Keywords: economic evaluation; cost utility; cataract surgery; elderly

Introduction

Poor vision is a risk factor for falling ${ }^{1}$ and falls can cause major clinical injuries, hospital admissions, and independence problems. We previously demonstrated that first-eye cataract surgery while just cost-ineffective in the short term did appear cost-effective when modelled over the longer term. ${ }^{2,3}$ Bilateral cataracts are the biggest cause of poor vision in elderly patients. ${ }^{4}$ Current NHS practice is to operate on each eye separately, and increasing numbers are having the surgery performed at an earlier stage when vision may be of driving standard or better at the time of the operation leading to concerns of overutilization. ${ }^{5-7}$ The benefit of surgery for severe bilateral cataract is obvious, but it is less clear whether it is cost-effective to be operating on patients who already have good acuity following first-eye surgery.

Assessing the value for money afforded by an intervention is important, because the resources available to the NHS are fixed such that by spending money on second-eye cataract surgery we cannot use those same resources to treat something else which may afford a greater health benefit. Earlier research on the cost-effectiveness of cataract surgery is sparse (Lansingh et $a l^{8}$ incorporated just 
five cost-utility analyses of first-eye cataract surgery into a meta analysis) with most focusing on first-eye cataract surgery and relying on short-term non-randomized study designs. One other study ${ }^{9}$ has previously been published estimating the cost utility of second-eye cataract surgery in the United States. This study undertook econometric modelling using published data to determine the cost per quality-adjusted life year (QALY) for a 12 year life expectancy. They estimated the cost per QALY as \$2727 (US\$2001, 3\% discount rate for costs and QALYs), and concluded that second-eye cataract surgery was highly cost-effective compared with interventions in other medical areas and only slightly less cost-effective than first-eye cataract surgery (US\$2023). ${ }^{9}$

We previously demonstrated that second-eye cataract surgery improves visual disability and general health status (although with an uncertain effect on rate of falling). ${ }^{10}$ In this paper, we present an economic evaluation of second-eye surgery compared to first-eye surgery only (which represents what would be 'usual care' should second-eye cataract surgery not be performed), performing a cost-utility analysis from an NHS and personal social services perspective. Carers' costs are presented separately.

\section{Materials and methods}

\section{Participants and randomization}

Participants were women over 70 years of age who had previously had successful first-eye cataract surgery and who had a second operable cataract. Women were excluded if they had complex cataracts, visual field defects, severe co-morbid eye disease, or memory problems that would prevent the completion of study questionnaires. Ethical committee approval was granted, and participants gave informed, written consent.

Participants were randomized to immediate second-eye cataract surgery (median time to surgery 30 days, range 8-204), or no surgery ('waiting list' controls, median 316 days, range 37-527). Approximately $86 \%$ of participants had baseline acuity of $6 / 12$ or better and thus can be seen to have had good vision in the eye to be operated upon at baseline. This is an important group to study given recent concerns about overutilization of cataract surgery as a result of a reduction in the visual function threshold required for surgery to take place. Further details of the clinical trial have been published elsewhere. ${ }^{10}$

\section{Resource use and costing}

Patient diaries were used to collect individual patient level data on all contacts with health and social services, including care home admissions, use of informal care, equipment provided, and home modifications. Data were ascertained at 3 and 9 months through telephone interviews, and at 6 and 12 months through face-to-face interviews (Table 1). It was assumed that all equipment and modifications were paid for by social services with unit costs from the Personal Social Services Research Unit, where available, ${ }^{11}$ and otherwise from Internet mobility store price catalogues. Average net weekly earnings ${ }^{12}$ were applied to the time costs of informal carers, consistent with the human capital approach (Table 1). However, because the methods to cost time costs are controversial, ${ }^{14}$ carer costs were excluded from the base case as suggested by $\mathrm{NICE}^{15}$ but reported separately. All costs in this paper are presented in $£ 2004$ (inflated using the Hospital and Community Health Services inflation index, ${ }^{11}$ where necessary).

\section{Outcomes}

Patient utility was estimated using the EuroQol EQ-5D (www.euroqol.org), administered at baseline and at 6 months. The EQ-5D has five dimensions (mobility, self-care, usual activities, pain/discomfort, and anxiety/ depression), each with three possible severity levels (none, some, and severe problems). ${ }^{16}$ Combining these dimensions and levels creates 243 possible health states. Each health state has an empirically measured utility score assigned, ${ }^{17}$ measured using the time-trade-off technique. ${ }^{18}$ In the base case, patient-specific utility paths were created by assuming the 6-month utility value would apply 1 month after surgery (because the benefits are likely to be felt soon after surgery) and remained constant over the remaining 11 months.

Using area under the curve analysis, taking account of baseline, we estimated the number of QALYs for the 12-month trial period for each patient. The difference in mean QALYs per patient between surgery and no surgery was calculated. The benefits were not discounted as the study was for a single year period.

\section{Modelling longer-term cost utility}

The benefits of cataract operations are lifelong. ${ }^{8}$ Using each participant's estimated life expectancy (based on age and gender) from UK government life tables, a long-term analysis was undertaken to estimate lifetime costs and benefits. ${ }^{19}$ Annual costs for the control group were assumed to remain constant in subsequent years as that observed in the trial period. Costs were significantly higher in the first quarter compared to each subsequent quarter for the intervention group $(P<0.001)$, therefore the costs in the final three quarters of the year were rescaled to better reflect costs over a full year without a 
Table 1 Base-case unit costs in $£ 2004$

\begin{tabular}{|c|c|c|}
\hline Resource item & $\begin{array}{l}\text { Unit } \cos ^{\mathrm{a}} \\
(\mathfrak{(})\end{array}$ & Source \\
\hline \multicolumn{3}{|l|}{ Primary health care } \\
\hline GP (per surgery consultation lasting $9.36 \mathrm{~min}$ ) & 21 & PSSRU $^{11}$ \\
\hline Practice nurse/district nurse (per consultation) & 9 & PSSRU \\
\hline \multicolumn{3}{|l|}{ Secondary health care } \\
\hline A\&E (per visit) & 83 & PSSRU \\
\hline Outpatients first visit (geriatric medicine) & 222 & $\mathrm{DH}^{13}$ \\
\hline Outpatients follow-up visit (geriatric medicine) & 125 & $\mathrm{DH}$ \\
\hline Cost per bed day for elderly patients & 166 & PSSRU \\
\hline Cataract operation & 672 & $\mathrm{DH}$ \\
\hline Lower limb fractures (day case) & 777 & $\mathrm{DH}$ \\
\hline Upper limb fractures (day case) & 858 & $\mathrm{DH}$ \\
\hline \multicolumn{3}{|l|}{ Personal social services } \\
\hline Local authority home care worker (per visit) & 12 & PSSRU \\
\hline Day centre visits (per visit) & 29 & PSSRU \\
\hline Short-term residential care (per day) & 56 & PSSRU \\
\hline Long-term residential care (per day) & 53 & PSSRU \\
\hline Short-term nursing home (per day) & 73 & PSSRU \\
\hline Long-term nursing home (per day) & 75 & PSSRU \\
\hline Meals on wheels (per meal) & 2.60 & Wiltshire foods \\
\hline Special equipment (per item) (items ranged from & $4.10-499$ & Varied (available from author) \\
\hline \multicolumn{3}{|l|}{ long-handled sponge to electric buggy) } \\
\hline \multicolumn{3}{|l|}{ Patient and carer } \\
\hline Independently provided home care (per visit) & 10 & PSSRU \\
\hline $\begin{array}{l}\text { Average net weekly earnings (all ages, excluding } \\
\text { overtime and minus 35\% for income tax, NI and pension) }\end{array}$ & 320.95 & $\mathrm{NES}^{\mathrm{a}, 12}$ \\
\hline
\end{tabular}

aNew Earnings survey 2003, inflated to 2004 wage rates using earnings inflation rate of 0.045 .

cataract operation. As with the control group, these were assumed to remain constant over the remaining lifespan.

Without cataract surgery, vision in the affected eye is likely to continue to deteriorate, and so lead to declining utility over time. However, there is little evidence about this gradient of decline in vision, and the impact of this on utility over time. Consequently, to estimate the utility gain after the last study follow-up point, in line with other economic studies, ${ }^{20,21}$ we assumed that utility remained constant over the remaining lifetime for both groups. This is equivalent to assuming that the incremental effect (the difference in utility between the intervention and control group) is constant over remaining lifetime expectancy. Such an assumption is conservative and likely to underestimate the true gain from second-eye cataract surgery. In this lifetime analysis, both costs and benefits were discounted using a rate of $3.5 \%$ per annum in the base-case analysis. ${ }^{15,22}$

\section{Statistical analysis}

Ten patients (4.2\%) did not complete the 6-month EQ-5D questionnaire and were excluded. Patients with missing resource use data at one or more time points (around
$5 \%$ of the sample due to death between data collection points or early withdrawal) were imputed using the last observed value carried forward approach and apportioned for the appropriate period. Ten participants (three who declined early surgery and seven who had early non-trial surgery) were analysed using intention to treat.

The mean difference in cost and QALYs between groups was used to generate an incremental cost-effectiveness ratio (ICER). Non-parametric bootstrap analysis was undertaken to produce cost-effectiveness acceptability curves (CEACs), where a CEAC shows the probability of an intervention being cost-effective compared to the control group for different levels of willingness to pay (WTP) per QALY. ${ }^{23}$ However, assuming one seeks to maximize health subject to a budget constraint, then the decision with regard to cost-effectiveness should be made upon the basis of the ICER, where the CEAC represents the uncertainty associated with this decision. ${ }^{23}$

\section{Sensitivity analysis}

Sensitivity analyses were performed to test the robustness of both the short- and the long-term results. 
We undertook threshold analysis to find the price of cataract surgery (the single largest unit cost) that would make it cost-effective. The time course of the gain in health-related quality of life was assumed to occur at 1 month after surgery in the base case. We tested this assumption by changing the time course of gain in health-related quality of life to immediately after the operation and gradually over 6 months. Finally, in the longer-term modelling we tested the impact of varying the discount rate from the $3.5 \%$ assumed in the base case to 0 and $5 \%$, as recommended. ${ }^{24}$

We certify that all applicable institutional and governmental regulations concerning the ethical use of human volunteers were followed during this research.

\section{Results}

Data from 229 participants (116 intervention and 113 control) were included in the economic analysis. At baseline the groups were well matched. ${ }^{10}$

\section{Resource use and costs}

There were no statistically significant differences in resource use between groups at baseline. Post-intervention overall service use was higher in the operated group in the year after randomization, particularly in the first 3 months after surgery (2.8 times higher, $P<0.001)$. Costs over months 4-12 were not statistically significantly different between groups. Seven control group patients had surgery early; the costs of this surgery were included in the analysis such that the mean resource use and cost reported, for that category, in Table 2 is not zero.

The greatest resource use and cost was for the cataract operation and hospital outpatient visits (non-cataract related) (see Table 2). The mean total cost per patient (excluding carer time costs) in the operated group was $£ 2139$ (SD 1608) compared to $£ 1492$ (SD 282) in the control group (difference $£ 646,95 \%$ confidence interval, $£ 16-1276, P=0.04$ ). Total secondary care costs ( $£ 1590$ vs $632, P<0.001)$ and total primary health care costs ( $£ 138$ vs $110, P=0.04$ ) were also higher in the operated group. There was no statistically significant difference for personal social service costs ( $£ 411$ vs $750, P=0.190)$ or carer time costs ( $£ 575$ vs $364, P=0.14$ ).

\section{Cost-utility results without carer time costs included}

The mean difference in QALYs per patient in the base case was 0.015 (95\% confidence interval -0.039 to 0.068 , $P=0.59)$. The ICER for surgery in the base case was

Table 2 Mean (SD) resource use and cost per patient over the 12 months for second-eye cataract surgery and no second-eye cataract surgery

\begin{tabular}{|c|c|c|c|c|c|c|}
\hline \multirow[t]{2}{*}{ Resource use item } & \multicolumn{2}{|c|}{ Surgery $(\mathrm{n}=116)$} & \multicolumn{2}{|c|}{ No surgery $(\mathrm{n}=113)$} & \multicolumn{2}{|c|}{ Mean difference $(95 \% \mathrm{CI})$} \\
\hline & Resource & Cost $(£)$ & Resource & Cost $(£)$ & Resource & Cost $(£)$ \\
\hline Secondary health care & & $1590(999)$ & & $632(1110)$ & & 958 (683 to 1234$)$ \\
\hline Cataract operation (per operation) & $1(0.00)$ & $672(0)$ & $0.04(0.21)$ & $30(139)$ & $0.96(0.92$ to 0.99$)$ & 643 (617 to 669$)$ \\
\hline $\begin{array}{l}\text { Non-cataract-related outpatients } \\
\text { first and follow-up visit (no.) }\end{array}$ & $6.94(5.71)$ & $544(392)$ & $2.81(5.07)$ & $291(371)$ & $4.13(2.72$ to 5.53$)$ & 252 (153 to 352$)$ \\
\hline Bed days (no.) & $1.98(4.73)$ & $329(785)$ & $1.79(5.92)$ & $297(982)$ & $0.20(-1.20$ to 1.59$)$ & $32(-200$ to 264$)$ \\
\hline A\&E (no.) & $0.29(0.59)$ & $24(49)$ & $0.09(0.29)$ & $7(24)$ & 0.21 (0.08 to 0.33$)$ & 17 (7 to 27$)$ \\
\hline Lower limb fractures (no.) & $0.02(0.13)$ & $13(102)$ & $0.01(0.09)$ & $7(73)$ & 0.01 ( -0.02 to 0.04$)$ & $7(-16$ to 30$)$ \\
\hline Upper limb fractures (no.) & $0.01(0.09)$ & $7(80)$ & $0.00(0.00)$ & $0(0)$ & 0.01 ( -0.01 to 0.03$)$ & -7 ( -7 to 22$)$ \\
\hline Primary health care & & $138(104)$ & & $110(97)$ & & 28 (1 to 54$)$ \\
\hline GP (no. of visits) & $4.44(3.61)$ & $£ 93(£ 76)$ & $4.00(3.73)$ & $84(78)$ & $0.44(-0.52$ to 1.40$)$ & $9(-11$ to 29$)$ \\
\hline Practice/district nurse (no. of visits) & $4.97(7.49)$ & $45(67)$ & $2.93(3.80)$ & $26(34)$ & 2.05 (0.501 to 3.59$)$ & 18 (5 to 32$)$ \\
\hline Personal social services & & 411 (998) & & $750(2560)$ & & $-340(-850$ to 171$)$ \\
\hline LA home care worker (no. of hours) & $1.54(3.64)$ & $241(568)$ & $1.51(4.06)$ & $235(633)$ & 0.03 (-0.97 to 1.04$)$ & $5(-152$ to 162$)$ \\
\hline Day centre visits (no. of days) & $8.52(46.48)$ & $62(337)$ & $16.11(72.57)$ & $117(526)$ & $-5.79(-23.52$ to 8.34$)$ & $55(-171$ to 60$)$ \\
\hline Residential care (no. of days) & $0.80(6.89)$ & $45(389)$ & $5.68(41.86)$ & $321(2362)$ & $-4.88(-12.78$ to 3.02$)$ & $-275(-721$ to 170$)$ \\
\hline Nursing home care (no. of days) & $0.09(0.66)$ & $7(48)$ & $0.00(0.00)$ & $0(0)$ & 0.09 ( -0.06 to 0.22$)$ & $-7(-2$ to 16$)$ \\
\hline Meals on wheels (no. of days) & $15.69(75.81)$ & $31(148)$ & $27.15(148.56)$ & $53(290)$ & $-11.46(-42.36$ to 19.43$)$ & $22(-83$ to 38$)$ \\
\hline Special equipment (no. of items) & $0.47(1.33)$ & $25(85)$ & $0.39(0.91)$ & $24(87)$ & $0.08(-0.22$ to 0.37$)$ & $-1(-21$ to 24$)$ \\
\hline Patient and carer & & 575 (1239) & & $364(867)$ & & $210(-68$ to 488$)$ \\
\hline Home care (no. of hours) & $215.43(477.17)$ & 539 (1193) & $125.01(303.59)$ & $313(759)$ & $90.42(-13.54$ to 194.37$)$ & $226(-34$ to 486$)$ \\
\hline $\begin{array}{l}\text { Carer time costs (no. stopped } \\
\text { working) }\end{array}$ & $0.00(0.00)$ & $36(686)$ & $0.00(0.00)$ & $52(421)$ & 0.00 & $-16(-121$ to 90$)$ \\
\hline
\end{tabular}

No., number.

Bold face represents the summaries for the category headings. 


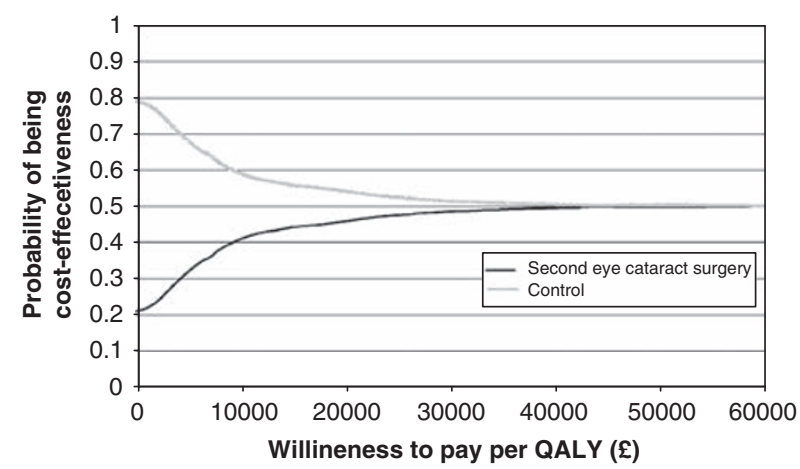

Figure 1 Cost-effectiveness acceptability curve for second-eye cataract surgery $v s$ control in the short term.

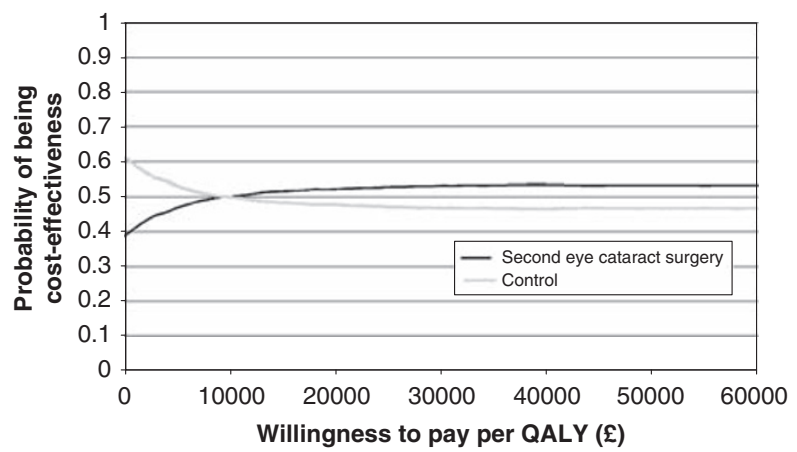

Figure 2 Cost-effectiveness acceptability curve for second-eye cataract surgery $v s$ control in the long term.

Table 3 Summary of ICERs for second-eye cataract surgery (in £2004)

\begin{tabular}{lll}
\hline & $\begin{array}{l}\text { ICER over } \\
\text { the 1-year } \\
\text { trial period }\end{array}$ & $\begin{array}{l}\text { ICER over lifetime at 3.5\% } \\
\text { discount rate (0\% discount } \\
\text { rate, 5\% discount rate) }\end{array}$ \\
\hline Base case, public sector costs only & $£ 44263$ & $£ 17299(£ 21046, £ 16134)$ \\
Base case, carer costs included & $£ 58667$ & $£ 41973(£ 49154, £ 39694)$ \\
QoL improvement applies from time of operation, public sector costs only & $£ 42271$ & $£ 17151(£ 20871, £ 15994)$ \\
QoL improvement applies from time of operation, carer costs included & $£ 56027$ & $£ 41613(£ 48745, £ 39348)$ \\
QoL improvement gradual over 6 months, public sector costs only & $£ 56085$ & $£ 18073(£ 21955, £ 16871)$ \\
QoL improvement gradual over 6 months, carer costs included & $£ 74336$ & $£ 43853(£ 51277, £ 41507)$ \\
\hline
\end{tabular}

$£ 44263$. Figure 1 shows the CEAC for the first year after surgery. At a WTP of $£ 30000$ per QALY there is a $49 \%$ chance of second-eye cataract surgery being cost-effective in this population.

\section{Cost-utility results with carer time costs included}

Surgery remained more costly than control ( $£ 2713$ vs 1857), and the mean cost difference ( $£ 857$; 95\% confidence interval, $£ 145-1568, P=0.019)$ was higher. Incremental cost-effectiveness with carer time cost incorporated was $£ 58667$.

\section{Modelling longer-term cost utility}

Extrapolating beyond the trial period to assume a time frame for analysis over expected remaining lifetime revealed a mean total cost per patient of $£ 12171$ (SD 16042) operated, compared with $£ 10887$ (SD 19823) control, mean difference of $£ 1284$ (95\% confidence interval $-£ 3420$ to $£ 5.989, P=0.591$ ). The mean difference in QALYs per patient was 0.074 (95\% confidence interval -0.38 to $0.53, P=0.75$ ), with a long-term ICER of $£ 17299$ when a public sector (health and social care) perspective was taken, and this mean difference applied over the remaining life expectancy. (In fact, in the 6 months utility was measured in the trial it deteriorated in the control group from 0.72 to 0.69 ). The long-term ICER was $£ 41973$ when carer costs were included and benefits assumed to occur 1 month after surgery (Table 3). Figure 2 shows the CEAC for the longer-term model without carer costs. At a WTP of $£ 30000$ per QALY, there is a $52 \%$ chance of cataract surgery being cost-effective in this population.

\section{Sensitivity analysis}

The incremental cost-utility ratios for various assumptions and sensitivity analyses are given in Table 3. The unit cost threshold for the cataract operation itself, at which the ICER fell beneath $£ 30000$ was $£ 454$ (68\% of the actual cost) for the trial period analysis. Changing the assumptions about the time course of improvement after surgery had little effect on conclusions in the trial period or longer-term analysis. Changing the discount rate from 3.5 to 0 or $5 \%$ in the longer-term modelling is unlikely to change decisions based on the ICER (see Table 3).

\section{Conclusion}

Although second-eye cataract surgery improves visual disability and general health status, ${ }^{10}$ it does so at a cost. Combining the mean change in cost and QALYs 
revealed that the cost-effectiveness of second-eye cataract surgery in those with good visual acuity at baseline in the short term is in excess of the implicit £20000-30000 WTP threshold value used by NICE ${ }^{15}$ for UK health policy purposes. However, in the longer term (over the remaining lifetime of the woman), surgery is cost-effective at a WTP threshold of $£ 20000$ if a health and social services perspective is taken.

Second-eye cataract surgery was less cost-effective than first-eye cataract surgery in women with good baseline visual acuity, ${ }^{3}$ as others have found. ${ }^{9}$ However, the uncertainty around our results is greater than that for first-eye cataract surgery, as shown by the CEACs in both the short and the long-term analyses. This may suggest a need for further research in this area, using a large sample of patients, to reduce the uncertainty surrounding the cost-effectiveness of second-eye cataract surgery in those with minimal visual impairment pre-surgery.

We did not find second-eye cataract surgery to be as cost-effective over the longer term as described by Busbee et $a l^{9}$. The difference in our results may be because we used different patient populations (it is not clear whether the different data sources used by Busbee et $a l^{9}$ all relate to the same population, for instance) or different methods. In contrast to most other economic evaluations of cataract surgery, ${ }^{8}$ the study reported in this paper was undertaken alongside a randomized controlled trial for a 1-year follow-up period taking an NHS and personal social services perspective in the base case and in addition looked at carer costs. This means that utility estimates were derived from the cataract patients themselves, as opposed to from general ophthalmic patients. $^{9}$

The literature does, however, highlight some potential limitations of using patient-reported outcome measures (PROMs), such as the EQ-5D to elicit utility and consequently to estimate QALYs, in the area of cataract surgery and other sensory-related interventions. Issues in the use of such measures in this area include, for example, that utility may be driven by the level of vision in the good eye, ${ }^{25}$ problems of practicality where respondents with vision problems cannot self-complete the questionnaires and concerns over the impact of adaptation to disability on pre-operative measures.,26 Although the EQ-5D is widely used, ${ }^{27}$ and, to ensure consistency, is recommended for use in cost-effectiveness analyses by $\mathrm{NICE},{ }^{15}$ there is a specific concern that because each dimension only has three levels of severity it may lack precision and responsiveness, making it hard to detect small changes (this concern is not specific to just sensory disabilities). ${ }^{28}$ A recent report prepared for the Department of Health found that the EQ-5D was 'largely unresponsive' for cataract patients (p. 38), ${ }^{26}$ a point it argues is supported by other studies (note no papers were actually referenced to back up this statement) of interventions for vision and hearing. The report speculates that lack of responsiveness may relate to the fact that instruments such as the EQ-5D and SF-6D do not incorporate sensory functions as domains in their descriptive systems. ${ }^{26}$ It was on the basis of this report that the Department of Health for England and Wales recently decided to exclude the routine assessment of PROMs for cataract surgery from its guidance on PROMs in the NHS. ${ }^{7,29}$

A number of empirical studies have however used utility measures such as the EQ-5D. Many of these studies have found them sensitive to differences in visual acuity $^{25,30,31}$ or able to detect significant differences for sensory interventions, including cataracts. ${ }^{3,20,21,32}$ Indeed a study of first-eye cataract surgery in women with mild visual impairment found a statistically significant improvement in health status according to the EQ-5D because it captured the indirect health benefits of having the surgery. ${ }^{3}$ That is, the study reported a reduction in the number of falls experienced among those having the surgery which in turn led to reduced disability and ill-health by reducing the number of injuries such as fractures. ${ }^{3}$ Thus, the EQ-5D did detect the knock-on consequences of improved vision on health in this particular study. Therefore, it would appear wrong to conclude that instruments such as the EQ-5D cannot measure improvements in patients' health-related quality of life at all. ${ }^{7}$ However, given the importance such measures have in evaluating cost-effectiveness and in deciding resource allocation in the modern NHS (because they enable direct comparisons of value for money to be made across a wide range of interventions for different diseases and populations), it is important to ensure methodological work in this area continues to address the concerns. ${ }^{33-36}$

Our current findings diverge from our findings for first-eye surgery in terms of the importance of certain costs. For first-eye cataract surgery, personal social service costs were significantly higher for the surgery group rather than the control group and carer costs were lower for the surgery group than the control group. For second-eye cataract surgery, the reverse was found, personal social service costs were higher for the control group whereas carer costs were higher for the surgery group. This may suggest that there is likely to be some trade-off between these two types of support. The size of the difference in non-cataract-related outpatient first and follow-up visit costs is also noticeable between groups. We have no explanation for this, given the groups were well matched at baseline.

The study included a population with good acuity at baseline ( $86 \%$ better than Snellen $6 / 12$ at baseline), in one 
centre in the UK, so results may lack generalizability. Nonetheless this is an important population to study as they make up the majority of cases awaiting second-eye cataract surgery.

The long-term modelling used the real data we had from the 1-year trial period to extrapolate what might happen if patients were followed up over their remaining life expectancy. This analysis is by nature tentative and based upon assumptions, the main assumptions being that the control group would never undergo surgery for second-eye cataract and that the difference in quality of life, between the two groups, is constant over remaining lifespan. The former assumption estimates the cost-effectiveness of second-eye cataract surgery against never having second-eye cataract surgery rather than estimate the cost-effectiveness of the timing of the surgery. The second assumption, although somewhat unrealistic, is conservative, as vision ${ }^{10,37-39}$ and utility are likely to deteriorate in the control group over time (the mean declined from 0.72 to 0.69 in the 6-month period used to measure utility in this study), consequently the true gain in utility and true cost-effectiveness of second-eye cataract surgery in women with minimal visual impairment in the eye to be operated are likely to have been underestimated. Neither was adjustment made for the effect of increasing age on utility, because both groups would have been aging at the same rate. Given the lack of evidence about the rate of decline in vision and utility over the longer term from second-eye cataract problems for our particular sample, the longer-term model had to make some assumption about these. Rather than choosing an arbitrary rate of decline in vision and utility, which could lead to accusations of overly favouring the cost-effectiveness of second-eye surgery, we chose to take the conservative approach of assuming constant difference in utility between the two groups. In the event, we found it to be cost-effective in the long term from a public sector perspective even with such a conservative assumption. It was important to undertake this analysis, despite its limitations, because it is unrealistic to believe that cataract surgery is undertaken for 1-year gains in QALYs. In reality the benefits of cataract surgery are lifelong. However, clearly further empirical research on the long-term cost-effectiveness of second-eye cataract surgery is necessary.

The results suggest that second-eye cataract surgery is unlikely to be cost-effective (for those with minimal visual impairment pre-surgery) in the short term or in the long term if career costs are also included. The CEACs for both the short and the long term in the base case show a lot of uncertainty exists around this conclusion and are indicative of the need for more research.

\section{Acknowledgements}

We acknowledge the funding provided by the former Trent Regional NHS Research and Development scheme and the PPP Foundation (now the Health Foundation) that made the study possible. The funders had no role in the conduct, analysis or reporting of the study.

\section{References}

1 Masud T, Morris RO. Epidemiology of falls. Age Ageing 2001; 30(Suppl 4): 3-7.

2 Harwood RH, Foss AJ, Osborn F, , Gregson RM, Zaman A, Masud T. Falls and health status in elderly women following first eye cataract surgery: a randomised controlled trial. Br J Ophthalmol 2005; 89: 53-59.

3 Sach TH, Foss AJ, Gregson RM, Zaman A, Osborn F, Masud T et al. Falls and health status in elderly women following first eye cataract surgery: an economic evaluation conducted alongside a randomised controlled trial. $\mathrm{Br} \mathrm{J}$ Ophthalmol 2007; 91(12): 1675-1679.

4 Asbell PA, Dualan I, Mindel J, Brocks D, Ahmad M, Epstein S. Age-related cataract. Lancet 2005; 365: 599-609.

5 Desai P, Reidy A, Minassian DC. Profile of patients presenting for cataract surgery in the UK: national data collection. Br J Ophthalmol 1999; 83(8): 893-896.

6 Leinonen J, Laatikainen L. Changes in visual acuity of patients undergoing cataract surgery during the last two decades. Acta Ophthalmol Scand 2002; 80(5): 506-511.

7 Black N, Browne J, van der Meulen J, Jamieson L, Copley L, Lewsey J. Is there overutilisation of cataract surgery in England? Br J Opthalmol 2009; 93: 13-17.

8 Lansingh VC, Carter MJ, Martens M. Global cost-effectiveness of cataract surgery. Ophthalmology 2007; 114(9): 1670-1678.

9 Busbee BG, Brown MM, Brown GC, Sharma S. Cost-utility analysis of cataract surgery in the second eye. Ophthalmology 2003; 110(12): 2310-2317.

10 Foss AJ, Harwood RH, Osborn F, Gregson RM, Zaman A, Masud T. Falls and health status in elderly women following second eye cataract surgery: a randomised controlled trial. Age Ageing 2006; 35: 66-71.

11 Curtis L, Netten A Unit Costs of Health and Social Care 2004. Accessed on-line on 14th March 2006 at http:/ / www.pssru.ac.uk/pdf/uc2004/uc2004.pdf.

12 National Statistics. New Earnings Survey 2003. Accessed on-line on 21st February 2007 at: http://www.statistics.gov.uk/downloads/theme_labour/ NES2003_Analyses_For_Part-Time_Employees/Vol_F.pdf.

13 Department of Health. NHS reference costs 2003. Accessed online 13th October 2005 athttp:/ / www.dh.gov.uk/en/ Publicationsandstatistics/Publications/ PublicationsPolicyAnd Guidance/DH_4070195.

14 Sach TH, Whynes DK. Measuring indirect costs: is there a problem? Appl Health Econ Health Policy 2003; 2(3): 135-139.

15 NICE. Guide to the Methods of technology appraisal, June 2008. Accessed on-line on 21st July 2008 at: http:/ / www.nice.org.uk/media/B52/A7/ TAMethodsGuideUpdatedJune2008.pdf.

16 Brooks R. EuroQol: the current state of play. Health Policy 1996; 37: 53-72. 
17 Dolan P, Gudex C, Kind P, Williams A. A social tariff for the EuroQol: results from a UK general population survey (Discussion Paper 138). University of York: Centre for Health Economics1995. Accessed on-line on 21st February 2008 at: http://www.york.ac.uk/inst/che/pdf/DP138.pdf.

18 Torrance GW. Measurement of health state utilities for economic appraisal. J Health Econ 1986; 5: 1-30.

19 Government Actuary Department Interim life tables. Access on line on 16th November 2006 at: http:// www.gad.gov.uk/Demography\%20Data/Life\%20Tables/ Interim life tables.html.

20 Barton GR, Fortnum HM, Stacey PC, Summerfield Q. Hearing-impaired children in the UK, IV: Cost-effectiveness of paediatric cochlear implantation. Ear Hear 2006; 27: $575-588$.

21 UK Cochlear Implant Study Group. Criteria of candidacy for unilateral cochlear implantation in postlingually deafened adults II: cost-effectiveness analysis. Ear Hear 2004; 25: 336-360.

22 HM Treasury. Green Book. Appraisal and evaluation in central government, 2007. http://www.hm-treasury.gov uk/data_greenbook_index.htm (accessed 30th July 2008).

23 Barton GR, Briggs AH, Fenwick EA. Optimal cost-effectiveness decisions: the role of the cost-effectiveness acceptability curve (CEAC), the cost-effectiveness acceptability frontier (CEAF), and the expected value of perfection information (EVPI). Value Health 2008; 11: 886-897.

24 Drummond M, Sculpher M, Torrance GW, O'Brien BJ, Stoddart G. Methods for the Economic Evaluation of Health Care Programmes. 3rd edn. Oxford University Press: Oxford, New York, 2005.

25 Kobelt G, Jonsson B, Bergstrom A, Chen E, Linden C, Alm A. Cost-effectiveness analysis in glaucoma: what drives utility? Results from a pilot study in Sweden. Acta Ophthalmol Scand 2006; 84: 363-371.

26 Browne J, Jamiesin L, Lewsey J, Van der Meulen J, Black N, Cairns J et al. Patient Reported Outcome Measures (PROMs) in Elective Surgery: Report to the Department of Health. 2007. Accessed on-line on 8th April 2009: http://www/lshtm.ac.uk/hsru/research/ PROMs-Report-12-Dec-07.pdf.

27 Kind P. Size matters. EQ-5D in transition. Med Care 2007; 45: 809-811.
28 Pickard AS, De Leon MC, Kohlmann T, Cella D, Rosenbloom S. Psychometric comparison of the standard EQ-5D to a 5 level version in cancer patients. Med Care 2007; 45: 259-263.

29 Department of Health. Guidance on the routine collection of Patient Reported Outcome Measures (PROMs) For the NHS in England 2009/10. 8th December 2008.

30 Espallargues M, Czoski-Murray CJ, Bansback NJ, Carlton J, Lewis GM, Hughes LA et al. The impact of age-related macular degeneration on health status utility values. Invest Ophthalmol Vis Sci 2005; 46: 4016-4023.

31 Smith DH, Johnson ES, Russell A, Hazlehurst B, Muraki C, Nichols GA et al. Lower visual acuity predicts worse utility values among patients with type 2 diabetes. Qual Life Res 2008; 17: 1277-1284.

32 Lloyd A, Nafees B, Gavriel S, Rousculp MD, Boyet KS, Ahmed A. Health utility values associated with diabetic retinopathy. Diabet Med 2008; 25: 618-624.

33 Ferreira PL, Ferreira LN, Pereira LN. How consistent are health utility values? Qual Life Res 2008; 17: 1031-1042.

34 van Nipen RMA, de Boer MR, Hoeijmakers JGJ, Ringens PJ, van Rens GHMB. Co-morbidity and visual acuity are risk factors for health-related quality of life decline: five-month follow-up EQ-5D data of visually impaired older patients. Health Qual Life Outcomes 2009; 7: 18.

35 Barton GR, Bankart J, Davis AC. A comparison of the quality of life of hearing-impaired people as estimated by three different utility measures. Int J Audiol 2005; 44: 1-7.

36 Barton GR, Bankart J, Davis A, Summerfield Q. Comparing utility scores before and after hearing aid provision: results according to the EQ-5D, HUI3, and SF-6D. Applied Health Econ Health Policy 2004; 3: 103-105.

37 Leske MC, Chylack Jr LT, He Q, Wu SY, Schoenfeld E, Friend $\mathrm{J}$ et al. Incidence and progression of cortical and posterior subcapsular opacities: the Longitudinal Study of Cataract. The LSC Group. Ophthalmology 1997; 104: 1987-1993.

38 Leske MC, Wu SY, Nemesure B, Li X, Hennis A, Connell AM. Incidence and progression of lens opacities in the Barbados Eye Studies. Ophthalmology 2000; 107: 1267-1273.

39 Magno BV, Datiles MB, Lasa MS. Progression of lens opacities in cataract patients after one year. Acta Ophthalmol Scand 1995; 73: 45-49. 